\title{
A COMPARATIVE STUDY ON STAPHYLOCOCCUS AUREUS ISOLATED IN LAO PDR AND IN JAPAN
}

\author{
Naomi Higa', Noikaseumsy Sithivong ${ }^{2}$, and Masaaki Iwanaga ${ }^{1,3}$ \\ Received June 15 1994/Accepted July 281994
}

During the past decade in Japan, methicillin resistant Staphylococcus aureus (MRSA) has been recognized as one of the major pathogens for nosocomial infection $^{5,6)}$, and the lethal cases due to MRSA were occasionally seen ${ }^{4}$. Increasing of its isolation frequency was coincident with increasing use of third-generation cephem-antibiotics. Therefore, the careful use of these antibiotics is now recommended. MRSA may rarely be isolated in the area such as Lao PDR where the third generation cephems are not used. In this communication, the strains of $S$. aureus isolated in Lao PDR are described with reference to their drug sensitivities and coagulase types comparing to those in Japan.

Staphylococcus aureus isolated at Mahosoto Hospital, Vientiane, Laos and at the Ryukyu University Hospital, Okinawa, Japan were used. The 54 strains of Laos were isolated in 1993, and 95 strains of Japan were isolated in 1992.

Minimum inhibitory concentrations (MICs) of Erythromycin (EM), Tetracycline (TC), Ampicillin (ABPC), Cefdinir (CFDN), and Methicillin (DMPPC) were determined by plate dilution method. Two fold dilution series of each drug in heart infusion agar (HIA) was prepared with the drug concentration ranging from 100 to $0.2 \mu \mathrm{g} / \mathrm{ml}$. The concentration of $\mathrm{NaCl}$ in methicillin containing HIA plates was adjusted at $4 \%$. Cultures of the isolates in heart infusion broth at $37^{\circ} \mathrm{C}$ for $6 \mathrm{hr}$ were diluted 1 to 10 with normal saline solution (ca. $10^{7}$ / $\mathrm{ml}$ ), and were inoculated by using Microplanter (Sakuma Co. model MITP \#00257) on the drug containing HIA plates including a control plates without drug. MICs of each drug were evaluated after $24 \mathrm{hr}$ incubation at $37^{\circ} \mathrm{C}$.

Antigenic types of coagulase produced by the isolates were examined by neutralization test using "Coagulase Typing Immune Sera Kit" (Denka Seiken Co., Tokyo). Coagulation inhibition by adding anti-sera was examined using plastic microdilution plates ${ }^{7}$.
Drug sensitivity patterns of the isolates from Laos and Japan were clearly different from each other. $\mathrm{MIC}_{90}$ of $\mathrm{EM}$ was $0.4 \mu \mathrm{g} / \mathrm{ml}$ in Lao isolates but $100 \mu \mathrm{g} / \mathrm{ml}$ or more in Japanese isolates. Actually Japanese isolates revealed 2 peaks of susceptibility against EM (Fig. 1 -A). TC was less effective to Lao isolates. MICs of TC against $58 \%$ of Lao isolates and $25 \%$ of Japanese isolates were $12.5 \mu \mathrm{g} / \mathrm{ml}$ or more. (Fig. 1-B). MICs of ABPC showed a pattern of normal distribution with the frequent MIC of $3.13 \mu \mathrm{g} / \mathrm{ml}$ in Lao strains and $25 \mu \mathrm{g} / \mathrm{ml}$ in Japanese strains (Fig. 1-C). All Lao isolates were inhibited at $0.8 \mu \mathrm{g} / \mathrm{ml}$ or less of CFDN, whereas only $37 \%$ of Japanese isolates. Thirty-eight per cent of Japanese isolates were resistant to $100 \mu \mathrm{g} / \mathrm{ml}$ of CFDN (Fig. 1-D). All Lao isolates were inhibited at $6.25 \mu \mathrm{g} /$ $\mathrm{ml}$ or less of DMPPC, but $63 \%$ of Japanese isolates were not inhibited at $100 \mu \mathrm{g} / \mathrm{ml}$ of DMPPC (Fig. 1-E).

The most frequent antigen type of coagulase in Lao isolates was type 5 (54\%), and in Japanese isolates, it was type $2(53 \%)$. There were $11 \%$ of type 2 in Lao isolates and there were only $4 \%$ of type 5 in Japanese isolates (Table 1).

Table 1. Cagulase typing

\begin{tabular}{c|r|r|r|r}
\hline type & \multicolumn{2}{|c|}{ Laos } & \multicolumn{2}{|c}{ Japan } \\
\hline 1 & 0 & $0 \%$ & 1 & $1 \%$ \\
2 & 6 & $11 \%$ & 50 & $53 \%$ \\
3 & 6 & $11 \%$ & 18 & $19 \%$ \\
4 & 2 & $4 \%$ & 2 & $2 \%$ \\
5 & 29 & $54 \%$ & 4 & $4 \%$ \\
6 & 0 & $0 \%$ & 1 & $1 \%$ \\
7 & 8 & $15 \%$ & 13 & $14 \%$ \\
8 & 1 & $2 \%$ & 0 & $0 \%$ \\
NT & 2 & $4 \%$ & 6 & $6 \%$ \\
\hline total & 54 & $100 \%$ & 95 & $100 \%$ \\
\hline
\end{tabular}

In Lao PDR, Mahosoto Hospital is the greatest hospital in the viewpoints of its size and function. Antibiotics being used over there are penicillin-G, amox-

Department of Bacteriology ${ }^{1}$ and Research Center of Comprehenisive Medicine ${ }^{3}$, Faculty of Medicine,

University of the Ryukyus; 207 Uehara, Nishihara, Okinawa 903-01, Japan.

National Institute of Hygiene and Epidemiology², Vientiane, People's Democratic Republic of Laos. 

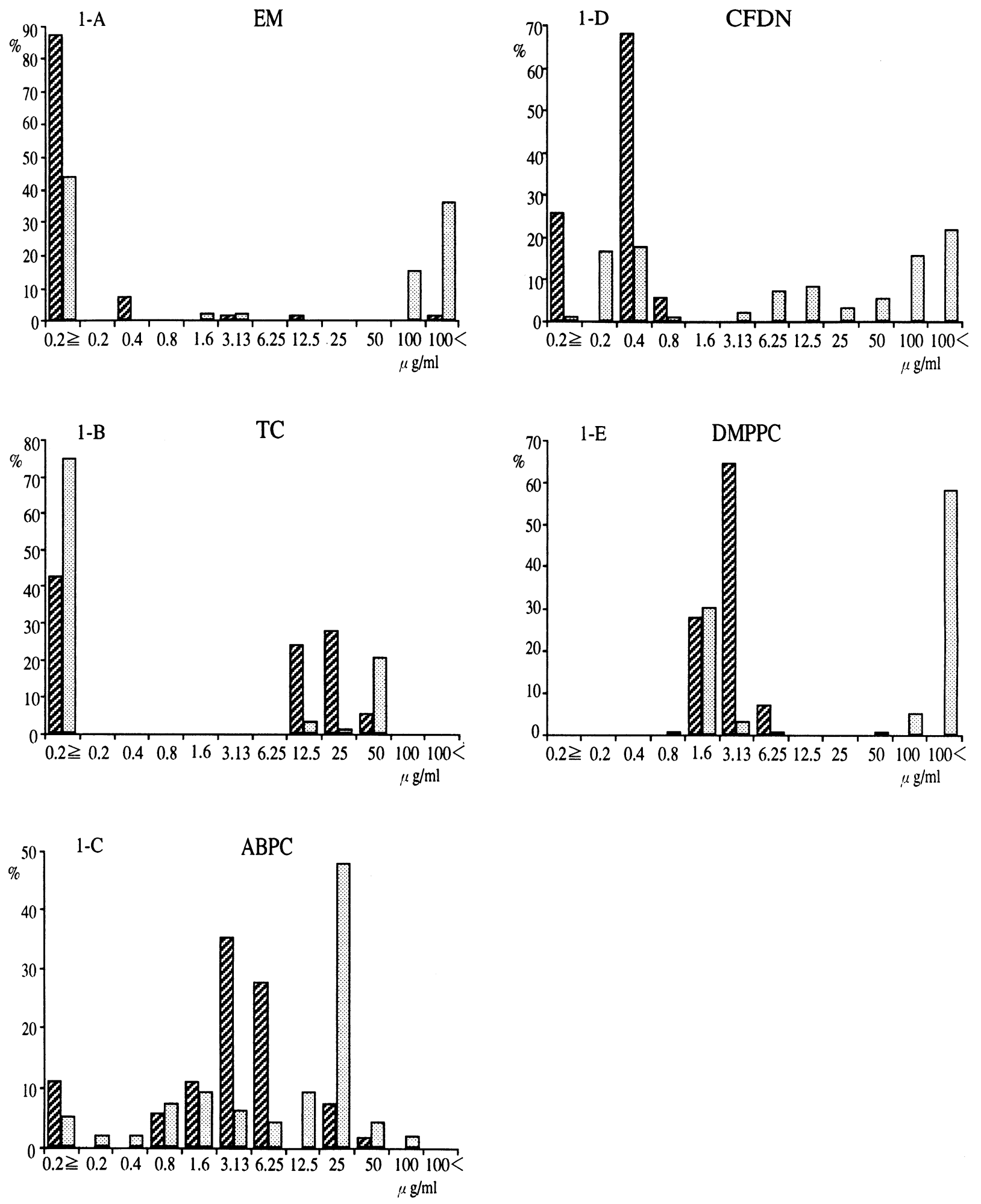

Fig. 1 MIC of A: Erithromycin, B: Tetracycline, C: Ampicillin, D: Cefdinir, E: Methicillin $\square$ Laos Japan 
icillin, tetracycline, chloramphenicol, gentamicin, nalidixic acid, and erythromycin. Among them, ampicillin and tetracycline are most frequently used. Reflecting this background, considerable number of $S$. aureus resistant to these two drugs were isolated. Erythromycin is less frequently used in Laos because of its price, and there were very few resistant isolates. It is noteworthy that there was no MRSA in the examined isolates from Lao. However, it is no wonder because of the antibiotics consumption pattern in Laos. The third-generation cephems, which are closely related to the development of $\mathrm{MRSA}^{1,3)}$, might have never been used over there. The frequency of MRSA at Ryukyu University Hospital is in an average level of all Japan ${ }^{2}$. It is well recognized that nosocomial infection due to MRSA is a serious problem in the present Japan, however, there is no problem of this resistant organism in Laos. Reviewing the drug sensitivity pattern in Laos and Japan, we have to consider the proper use of antibiotics.

Coagulase type of $S$. aureus can be used for an epidemiological study. The most frequent coagulase type in Laos and Japan was type 5 (54\%) and type 2 $(53 \%)$, respectively. While, the frequency of type 5 in Japan was only $4 \%$ and type 2 in Laos was $11 \%$. It is not known what the type 5 means, but type 2 is closely related to MRSA. The relation between coagulase type and disease specificity should be considered.

\section{references}

1. Watanabe, A., Ohizumi, K., Aonuma, S., Ono, R., Honda, Y., Tokue, Y., Kitamura, N., Shoji, S. and Konno, K. (1989) : Studies on Multiple-Resistant Staphylococcus aureus (IV); Difference in Incidence of Methicillin -Resistant Staphylococcus aureus (MRSA) among Institutions, Departments and Specimens, Chemotheraphy, 37, $125-130$

2. Igari, J., Takamine, F. and Imamura, S. (1990) : Present Status of Methicillin-Resistant Staphylococcus aureus and Susceptibility to Anitimicrobial Agents in 6 Hospitals in Okinawa, Jpn. J. Clin. Pathol., 38, 975-982

3. Hori, K., Yura, J., Shinagawa, N., Sakurai, S., Mashita, K. and Mizuno, A. (1989) : Postoperative Enserocolitis and the Current Status of MRSA Enterocolitis -The Result of a Questionnaire Survey in Japan-, Kansensyougaku Zasshi, 63, 701-707

4. Wada, K., Suzuki, N., Kawashima, T., Tsukada, H., Ozaki, K. and Arakawa, M. (1992) : A Clinical Study of Bacteremia for the Recent Fifteen Years, Kansenshogaku Zasshi, 66, 620-627

5. Kusano, N. and Nakasone, I. (1990) : Nosocomial Infection with MRSA, Jpn. J. Clin. Pathol., 38, 990-997

6. Yokota, K. (1993) : Nosocomial infections, Nippon
Kosyu Eisei Zasshi, 40, 235-239

7. Tajima, Y., Nagasawa, Z., Tanabe, I., Yamada, H., Kusaba, K. and Tadano, J. (1992) : An Improved Method for the Serotyping of Free Coagulase from Staphylococcus aureus, Microbiol. Immunol., 36, 12331237 